\title{
OPEN Monocarborane cluster as a stable fluorine-free calcium battery electrolyte
}

\author{
Kazuaki Kisu ${ }^{\circledR}$, Sangryun $\mathrm{Kim}^{2}$, Takara Shinohara², Kun Zhao ${ }^{3}$, Andreas Züttel ${ }^{3}$ \& \\ Shin-ichi Orimo ${ }^{1,2} \bowtie$
}

High-energy-density and low-cost calcium (Ca) batteries have been proposed as 'beyond-Li-ion' electrochemical energy storage devices. However, they have seen limited progress due to challenges associated with developing electrolytes showing reductive/oxidative stabilities and high ionic conductivities. This paper describes a calcium monocarborane cluster salt in a mixed solvent as a Ca-battery electrolyte with high anodic stability (up to $4 \mathrm{~V}$ vs. $\mathrm{Ca}^{2+} / \mathrm{Ca}$ ), high ionic conductivity ( 4 $\mathrm{mS} \mathrm{cm}{ }^{-1}$ ), and high Coulombic efficiency for Ca plating/stripping at room temperature. The developed electrolyte is a promising candidate for use in room-temperature rechargeable Ca batteries.

Li-ion batteries with high energy densities are indispensable in applications such as portable electronic devices, electric vehicles, and grid-scale storage. However, current Li-ion battery technologies are approaching their theoretical energy density limits. In addition, there are critical challenges associated with natural abundance, cost, and safety ${ }^{1}$. A plausible solution to these issues is to use divalent batteries based on Ca or Mg metal anodes, because these elements are the fifth and seventh most abundant in Earth's crust, respectively. In particular, Ca has a low reduction potential $(-2.87 \mathrm{~V}$ vs. standard hydrogen electrode $(\mathrm{SHE}))$, similar to that of $\mathrm{Li}(-3.04 \mathrm{~V}$ vs. SHE) but much lower than that of $\mathrm{Mg}(-2.37 \mathrm{~V}$ vs. SHE). Furthermore, these divalent metals offer higher volumetric capacities (Ca: $2073 \mathrm{mAh} \mathrm{cm}^{-3}$; $\mathrm{Mg}: 3833 \mathrm{mAh} \mathrm{cm}^{-3}$ ) than $\mathrm{Li}^{2-5}$. Thus, the cell voltage and energy density of $\mathrm{Ca}$ batteries are expected to be comparable to and higher than those of Li-ion and $\mathrm{Mg}$ batteries, respectively. Moreover, as $\mathrm{Ca}^{2+}(1.12 \AA)$ has a larger ionic radius than that of $\mathrm{Mg}^{2+}(0.72 \AA)$, its charge polarization is reduced, and this ion softness tends to form more-covalent bonds with host anions, which may lead to improved ion transport and diffusion in electrolyte and cathode materials ${ }^{3,6}$. Therefore, rechargeable Ca batteries that exhibit not only the advantages of cost effectiveness and abundance but also the battery performances are attractive candidates for post-Li-ion battery technologies ${ }^{2,6-8}$.

Among the main challenges related to Ca-battery technology is a lack of suitable electrolytes for reversible Ca metal plating/stripping at room temperature ${ }^{9}$. Non-aqueous Ca electrolytes comprising conventional salts in aprotic solvents are fundamentally incompatible with Ca metal anodes because the passivating films that form on anode surfaces prevent $\mathrm{Ca}$ ion transport ${ }^{10}$. In the past few years, intensive research has been pursued to develop new electrolytes capable of reversible Ca plating/stripping. In 2016, reversible Ca plating/stripping was first reported in an electrolyte of $\mathrm{Ca}\left(\mathrm{BF}_{4}\right)_{2}$ in ethylene carbonate/propylene carbonate at $100^{\circ} \mathrm{C}^{11}$. The deposited product contained not only $\mathrm{Ca}$ metal but also $\mathrm{CaF}_{2}$, which inhibits Ca diffusion and hinders plating and stripping processes ${ }^{12}$.

More recently, Li et al. and Shyamsunder et al. simultaneously demonstrated that room-temperature reversible Ca plating/stripping using an electrolyte of $\mathrm{Ca}\left[\mathrm{B}(\mathrm{hfip})_{4}\right]_{2}$ (hfip = hexafluoroisopropyloxy) in 1,2-dimethoxyethane (DME) was possible with impressive anodic stability $(>4.0 \mathrm{~V})^{13,14}$. The $\left[\mathrm{B}(\mathrm{hfip})_{4}\right]$ anion is known to be a weakly coordinating anion with weak anion-cation interactions, thereby favouring ion association and higher conductivities ${ }^{15,16}$. Despite its excellent electrochemical performances, this electrolyte can intrinsically suffer from the same issue of $\mathrm{CaF}_{2}$ formation as the $\mathrm{Ca}\left(\mathrm{BF}_{4}\right)_{2}$ electrolyte. Wang et al. proposed $\mathrm{Ca}\left(\mathrm{BH}_{4}\right)_{2}$ in tetrahydrofuran (THF) as a fluorine-free electrolyte system, which showed a Coulombic efficiency of $95 \%$ during Ca plating/stripping on an Au electrode ${ }^{17}$. Although this electrolyte is compatible to Ca metal, the anodic stability is only $2.4 \mathrm{~V}$ vs. $\mathrm{Ca}^{2+} / \mathrm{Ca}$ because of the reducing nature of $\mathrm{BH}_{4}{ }^{-}$anions ${ }^{18,19}$. Thus, it is desirable to find

\footnotetext{
${ }^{1}$ Advanced Institute for Materials Research (WPI-AIMR), Tohoku University, Katahira 2-1-1, Aoba-ku, Sendai 980-8577, Japan. ${ }^{2}$ Institute for Materials Research (IMR), Tohoku University, Katahira 2-1-1, Aoba-ku, Sendai 980-8577, Japan. ${ }^{3}$ Laboratory of Materials for Renewable Energy, École Polytechnique Fédérale de Lausanne (EPFL), Valais/Wallis, Rue de I'Industrie 17, 1950 Sion, Switzerland. ${ }^{\boxplus}$ email: k.kisu@imr.tohoku.ac.jp; orimo@imr.tohoku.ac.jp
} 
a fluorine-free Ca electrolyte system that delivers high electrochemical performance, i.e. a wide electrochemical potential window, reversible Ca plating/stripping stability, and high ionic conductivity at room temperature.

Herein, we propose a fluorine-free Ca electrolyte using calcium monocarborane ( $\mathrm{CMC}$ or $\left.\mathrm{Ca}\left[\mathrm{CB}_{11} \mathrm{H}_{12}\right]_{2}\right)$, which shows a wide electrochemical potential window up to $4 \mathrm{~V} \mathrm{vs.} \mathrm{Ca}^{2+} / \mathrm{Ca}$ and high conductivity of $4 \mathrm{mS} \mathrm{cm}^{-1}$, in addition to supporting reversible Ca metal plating/stripping at room temperature. The monocarborane cluster anion $\left(\left[\mathrm{CB}_{11} \mathrm{H}_{12}\right]^{-}\right)$is a type of complex hydride anion, which is known as a weakly coordinating anion ${ }^{20-23}$. Moreover, due to its high reductive and oxidative stability, it allows for a wide potential window and shows excellent stability against metal anodes such as $\mathrm{Li}, \mathrm{Na}$, and $\mathrm{Mg}^{24-29}$. These led to the idea that an electrolyte with the $\left[\mathrm{CB}_{11} \mathrm{H}_{12}\right]^{-}$anion could also be highly compatible with $\mathrm{Ca}$ batteries. However, a design that incorporates a monocarborane cluster anion into a Ca electrolyte has not been proposed. In fact, the results of this study reveal that electrolytes prepared by simply adding a CMC salt to single DME or THF solvents show poor solubility and deliver insufficient electrochemical performance. Hence, we found that a DME/THF mixed solvent shows high solubility for the CMC salt and delivers excellent electrochemical performances in Ca batteries.

\section{Methods}

The preparations and handling of air-sensitive materials were conducted under a dry Ar atmosphere using a glovebox and Schlenk techniques.

Synthesis of CMC electrolytes. Hydrated CMC $\left(\mathrm{CMC} \cdot \mathrm{nH}_{2} \mathrm{O}\right)$ and anhydrous CMC were synthesised via ionic exchange and heat treatment ${ }^{30,31}$. First, $\mathrm{Cs}\left[\mathrm{CB}_{11} \mathrm{H}_{12}\right](2.759 \mathrm{~g}, 10 \mathrm{mmol}$, Katchem Ltd.) was converted into the corresponding acid $\left[\mathrm{H}_{3} \mathrm{O}\right]\left[\mathrm{CB}_{11} \mathrm{H}_{12}\right]$ through ion exchange(acidic form of Ambarlite IR120B, $20 \mathrm{~mL}$ ). Aqueous $\mathrm{Ca}\left[\mathrm{CB}_{11} \mathrm{H}_{12}\right]_{2}$ was prepared by neutralising $\left[\mathrm{H}_{3} \mathrm{O}\right]\left[\mathrm{CB}_{11} \mathrm{H}_{12}\right]$ with excess $\mathrm{CaCO}_{3}(1.501 \mathrm{~g}, 1.5 \mathrm{eq}$, FUJIFILM Wako Pure Chemical Co.). Solvent removal yielded hydrated CMC, which was further dried under vacuum $\left(<8 \times 10^{-4} \mathrm{~Pa}\right)$ at $433 \mathrm{~K}$ for $10 \mathrm{~h}$ to obtain $\mathrm{CMC}^{32}$. DME (Sigma-Aldrich), THF (Sigma-Aldrich), DME/THF mixed solvent, diglyme, and triglyme were stored over 3-A molecular sieves prior to use, yielding measured water levels of $<10 \mathrm{ppm}$. To prepare Ca electrolytes, CMC was dissolved in a volumetric flask with appropriate amounts of each solvent to achieve the desired or saturated concentration. The molar concentration of the electrolyte is based on the molar mass of CMC.

Physicochemical characterisations of the CMC electrolytes. The $\mathrm{Ca}, \mathrm{B}$, and residual Cs contents of the compounds were determined using inductively coupled plasma-optical emission spectrometry (ICP-OES) and inductively coupled plasma mass spectrometry (ICP-MS). Nuclear magnetic resonance (NMR) spectra (Bruker Avance II spectrometer) were obtained at 7.05 $\mathrm{T}$ for the ${ }^{1} \mathrm{H}$ and ${ }^{11} \mathrm{~B}$ nuclei. All samples were prepared using aceton- $d 6$ (Sigma-Aldrich) as the solvent. The vibrational modes of complex anions were characterised by Raman spectroscopy (DXR, Thermo Scientific). Prior to performing scanning electron microscopy (SEM) with energy-dispersive X-ray spectroscopy (EDS) analysis, all the samples were loaded in air-tight sample holders to prevent any exposure to ambient conditions during sample transfer. For the differential scanning calorimetry (DSC) measurements, samples weighing $4.02 \mathrm{mg}$ were transferred through the glovebox and measurements were conducted under Ar flow. After loading the samples in the DSC instrument, a heating programme from $\mathrm{T}=303$ to $\mathrm{T}=773 \mathrm{~K}$ with a heating rate of $\mathrm{dT} / \mathrm{dt}=2 \mathrm{~K} \mathrm{~min}^{-1}$ was started. A return programme for cooling was started sequentially at a cooling rate of $\mathrm{dT} / \mathrm{dt}=-2 \mathrm{~K} \mathrm{~min}^{-1}$. The saturated concentrations of CMC in DME, THF, and the DME/THF mixture were determined by performing ICP-OES measurements. The water contents were measured using a convertible Karl Fischer moisture meter (CA-200, Mitsubishi Chemical Analytech Co.,Ltd.).

Electrochemical analyses and battery tests. Disc-shaped working electrodes composed of $\mathrm{Au}, \mathrm{Pt}, \mathrm{Cu}$, and SUS (with diameters of $8.0 \mathrm{~mm}$ ) and the counter and reference comprising Ca (with sizes of diameters of $10.0 \mathrm{~mm}$ and diameters of $5.0 \mathrm{~mm}$, respectively) were extensively polished until a metallic lustre was achieved before each use. All the electrochemical analyses were performed at room temperature with a stainless-steel electrochemical cell holder. Cyclic voltammetry (CV) was conducted at $20 \mathrm{mV} \mathrm{s}^{-1}$ with the voltage ranging between - 0.4 and $4.0 \mathrm{~V}$ vs. $\mathrm{Ca}^{2+} / \mathrm{Ca}$. Ex-situ XRD measurement was performed using an X'PERT Pro diffractometer (PANalytical) with $\mathrm{Cu} \mathrm{Ka}$ radiation (wavelength $\lambda=1.5406 \AA$ for $\mathrm{K}_{\alpha 1}$ and $1.5444 \AA$ for $\mathrm{K}_{\alpha 2}$ ).

Sulfur/carbon (S/C) composites were prepared through mechanical milling using elemental sulfur $(99.98 \%$, Sigma-Aldrich), KETJEN BLACK (KB), and MAXSORB with a weight ratio of $2: 1: 1^{24,33}$. S/C electrodes were prepared by mixing $80 \mathrm{wt} \%$ of the composite and $20 \mathrm{wt} \%$ of weight of polyvinylidene difluoride (PVDF) in $\mathrm{N}$-methyl pyrrolidone. The mixture was coated on an etched $\mathrm{Al}$ foil (current collector) and dried at $353 \mathrm{~K}$ in a vacuum for $12 \mathrm{~h}$. For the battery tests, the S/C electrodes, separator, electrolyte, and Ca metal anode were placed in a stainless-steel electrochemical cell holder. The electrochemical measurements were conducted at a C-rate of $0.1 \mathrm{C}$ at room temperature in the voltage range of 3.2-0.5 V using a battery tester (580 Battery Test System, Scribner Associates).

$\mathrm{X}$-ray photoelectron spectroscopy (XPS) analyses of the pristine S/C electrode and S/C electrode after discharge at $0.5 \mathrm{~V}$ were performed using a PHI 5000 VersaProbe III instrument (ULVAC-PHI, Inc.). The conductivities of solid-phase CMC pellets $(8 \mathrm{~mm})$ pressed at $120 \mathrm{MPa}$ were measured using the AC impedance method that utilized $\mathrm{Au} / \mathrm{CMC} / \mathrm{Au}$ over a temperature range of 303-423 $\mathrm{K}$, with applied frequencies of $4 \mathrm{~Hz}$ to $1 \mathrm{MHz}$ that were produced using a frequency response analyzer (3532-80, HIOKI). 
a

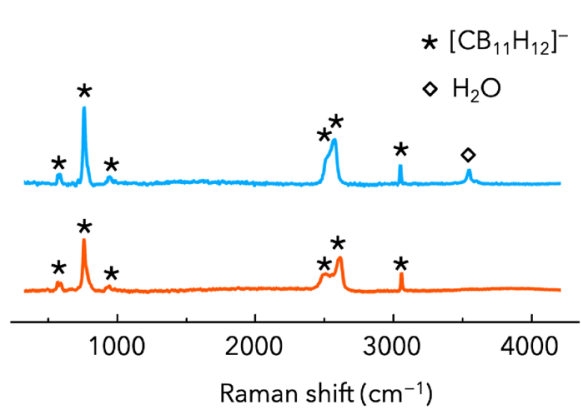

b

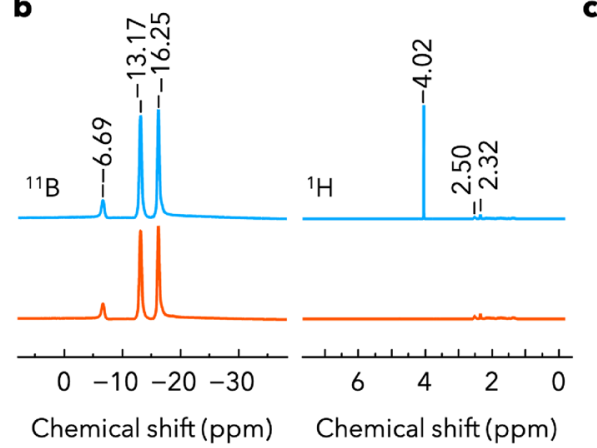

d

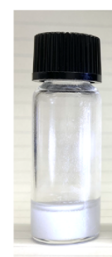

DME

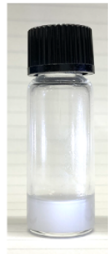

THF

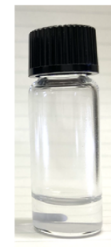

DME/THF e

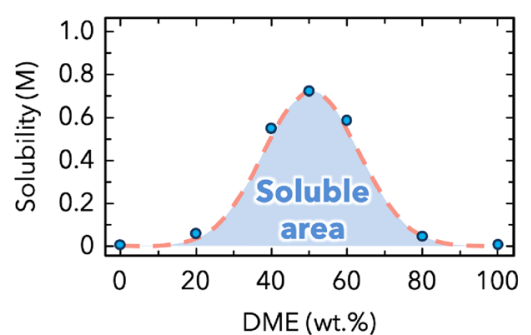

$\mathbf{f}$

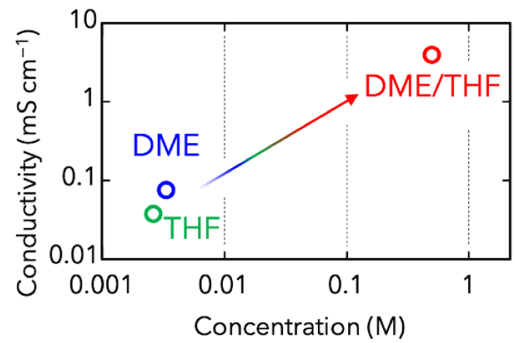

Figure 1. (a) Raman spectra of calcium monocarborane (CMC) (orange) and $\mathrm{CMC} \cdot \mathrm{nH}_{2} \mathrm{O}$ (blue). (b) ${ }^{11} \mathrm{~B}$ and ${ }^{1} \mathrm{H}$ nuclear magnetic resonance (NMR) spectra of $\mathrm{CMC}$ (orange) and $\mathrm{CMC} \cdot \mathrm{nH}_{2} \mathrm{O}$ (blue). (c) Geometry of the $\left[\mathrm{CB}_{11} \mathrm{H}_{12}\right]^{-}$anion (black, green, and blue spheres denote $\mathrm{C}, \mathrm{B}$, and $\mathrm{H}$ atoms, respectively). (d) Photographs of CMC dispersed/dissolved in 1,2-dimethoxyethane (DME), tetrahydrofuran (THF), and a DME/THF mixture. (e) Solubility diagram of CMC in mixtures of DME/THF with various solvent ratios. (f) Relationship between conductivity and CMC solubility (for details, see Table S2 and Fig. S2). The thermal stability is shown in Fig. S4. The conductivity of the solid phase CMC were measured by EIS and shown in Fig. S5.

\section{Results and discussion}

First, the atomic ratios of $\mathrm{Ca}, \mathrm{Cs}$, and $\mathrm{B}$ in $\mathrm{CMC}$ were determined through ICP-MS and ICP-OES (Table S1). As the $\mathrm{Cs} / \mathrm{Ca}$ ratio was less than $1 / 10,000$, the $\mathrm{Cs}$ salt was almost completely converted into Ca salt. Furthermore, the $\mathrm{Ca} / \mathrm{B}$ ratio was $1 / 21.96$, which is close to the theoretically determined ratio of $1 / 22$ in $\mathrm{CMC}\left(\mathrm{Ca}\left[\mathrm{CB}_{11} \mathrm{H}_{12}\right]_{2}\right)$. To characterize $\left[\mathrm{CB}_{11} \mathrm{H}_{12}\right]^{-}$anion and $\mathrm{H}_{2} \mathrm{O}$ in $\mathrm{CMC}$, Raman spectroscopy measurements and NMR measurements were assessed for $\mathrm{CMC}$ and $\mathrm{CMC} \cdot \mathrm{nH}_{2} \mathrm{O}$ (Fig. 1a,b). The Raman spectra of CMC and CMC $\cdot \mathrm{nH}_{2} \mathrm{O}$ exhibited various deformation vibration modes of $\left[\mathrm{CB}_{11} \mathrm{H}_{12}\right]^{-}$below $1200 \mathrm{~cm}^{-1}$. In addition, the Raman peak at $3050 \mathrm{~cm}^{-1}$ was ascribed to the $\mathrm{C}-\mathrm{H}$ stretching mode of $\left[\mathrm{CB}_{11} \mathrm{H}_{12}\right]^{-}$anion (Fig. 1c) ${ }^{34}$. The Raman peak observed at $3600 \mathrm{~cm}^{-1}$ for $\mathrm{CMC} \cdot \mathrm{nH}_{2} \mathrm{O}$, ascribed to the $\mathrm{O}-\mathrm{H}$ mode of $\mathrm{H}_{2} \mathrm{O}^{35}$, was not detected for $\mathrm{CMC}$, indicating that the hydrated water can be mostly removed from CMC by simply heating akin to the removal of the closo-type Ca complex hydride $\mathrm{CaB}_{12} \mathrm{H}_{12}{ }^{30,32}$. These results are consistent with the ${ }^{11} \mathrm{~B}$ and ${ }^{1} \mathrm{H}$ NMR spectra ${ }^{28,36}$. To investigate the water content in $\mathrm{CMC}$ and $\mathrm{CMC} \cdot \mathrm{nH}_{2} \mathrm{O}$ in detail, the Karl-Fischer titration method was applied for two electrolytes that were prepared from $5 \mathrm{~mL}$ of DME/THF (water content is less than $10 \mathrm{ppm}$ ) with $20 \mathrm{mg}$ of CMC or CMC $\cdot \mathrm{nH}_{2} \mathrm{O}$. The water content of CMC in DME/THF was measured as $15 \mathrm{ppm}$, while the water content of $\mathrm{CMC} \cdot \mathrm{nH}_{2} \mathrm{O}$ in DME/THF was measured as $1178 \mathrm{ppm}$. The difference of $5 \mathrm{ppm}$ in the water content would not affect battery operation; this difference can be compensated by the addition of molecular sieves to the CMC electrolyte. Upon the calculation of water content, $\mathrm{CMC} \cdot \mathrm{nH}_{2} \mathrm{O}$ can be expressed as $\mathrm{CMC} \cdot 6 \mathrm{H}_{2} \mathrm{O}$, which is consistent with the heattreatment-induced weight loss determined by thermogravimetric analysis (Fig. S1).

$\mathrm{Ca}$ electrolytes were prepared by dissolving CMC into the weakly coordinating solvents, which enabled the dissociation of Ca salts ${ }^{37-39}$. As the weakly coordinating solvents, THF, DME, and a mixture of DME/THF $(1: 1, v / v)$ were selected, and the solubilities of CMC were evaluated by ICP-OES using saturated solutions. Figure 1d shows photographs of $5 \mathrm{mg} \mathrm{CMC} \mathrm{dissolved} \mathrm{or} \mathrm{dispersed} \mathrm{in} 1 \mathrm{~mL}$ of solvent. Interestingly, although the solubilities of CMC in DME and THF were very low $(<0.0033$ and $0.0026 \mathrm{M}$, respectively), that in DME/THF was high $(>0.75 \mathrm{M})$. An investigation of the solubility behaviour of CMC in THF and DME binary mixtures was carried out at room temperature, where Fig. 1e shows the solubility diagram of CMC in DME/THF mixed solvents of various ratios. The highest solubility in the diagram is observed at a solvent ratio of approximately $1 / 1(\mathrm{v} / \mathrm{v})$. Similar improvements in solubility have been reported by using mixed solvents for several salts containing cluster-type complex hydride anions, such as $\mathrm{Mg}\left(\mathrm{CB}_{11} \mathrm{H}_{12}\right)_{2}, \mathrm{Li}_{2} \mathrm{~B}_{10} \mathrm{Cl}_{10}$, and $\mathrm{Li}_{2} \mathrm{~B}_{12} \mathrm{Cl}_{12}{ }^{29}, 40$. One of the possibility for the improved solubility observed in the present study is that the mixed solvents can be functionalized of the monocarborane cluster anion with one or more moieties ${ }^{41}$. The mechanism and role of the mixed solvent can be elucidated through quantum chemistry calculations and X-ray absorption spectroscopy of the electrolyte ${ }^{42,43}$, which will provide information about the coordination structure surrounding the $\mathrm{Ca}^{2+} \mathrm{cation}$ and the $\left[\mathrm{CB}_{11} \mathrm{H}_{12}\right]^{-}$anion; we plan to conduct such investigations in our future studies. These conductivities were 

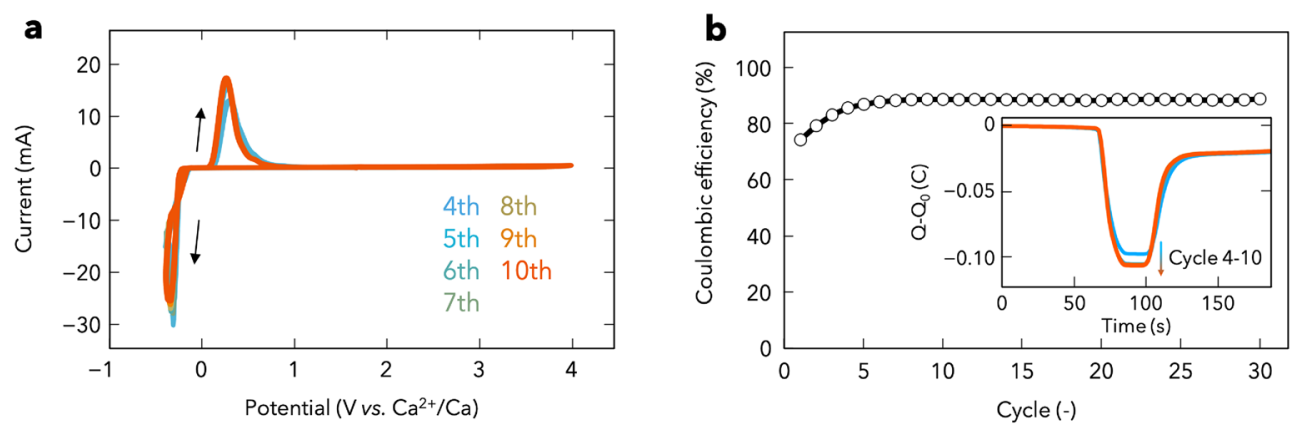

Figure 2. (a) Cyclic voltammograms of Ca plating/stripping after conditioning cycles at $20 \mathrm{mV} \mathrm{s}^{-1}$ with a three electrode setup using $\mathrm{Au}$ as the working electrode and $\mathrm{Ca}$ as the reference and counter electrodes at room temperature. Cyclic voltammograms for initial three cycles as conditioning processes are shown in Fig. S6. (b) Coulombic efficiency determined from the cyclic voltammograms. Inset: charge balance for cycles 4-10.

determined using a symmetrical cell with an Au electrode with the cell constant obtained via cell calibration using $0.08 \% \mathrm{KCl}$ and were used to calculate the conductivity of the electrolyte. The calculated conductivity of $0.5 \mathrm{M} \mathrm{CMC/DME} / \mathrm{THF}\left(4.0 \mathrm{mS} \mathrm{cm}{ }^{-1}\right)$ was greater than those of CMC/DME $\left(0.073 \mathrm{mS} \mathrm{cm}^{-1}\right)$ and CMC/THF $\left(0.036 \mathrm{mS} \mathrm{cm}^{-1}\right)$, and of the same order as that of the previously reported $\mathrm{Ca}\left[\mathrm{B}(\mathrm{hfip})_{4}\right]_{2}$ electrolyte (Figs. 1f, S2, S3 and Table S2) ${ }^{13}$.

Electrochemical studies were conducted using 0.5 M CMC/DME/THF. Ca plating/stripping was performed via $\mathrm{CV}$ at $20 \mathrm{mV} \mathrm{s}^{-1}$ with three-electrode setup using Ca metal as the reference and counter electrodes, and $\mathrm{Au}$ metal as the working electrode. Typical metal plating/stripping behaviour was observed in the cathodic/anodic scans (Fig. 2a). Ca plating commenced at $-220 \mathrm{mV}$ in the cathodic scan, and in the anodic scan, the current began to rise at $\sim 80 \mathrm{mV}$, indicating the stripping of plated Ca. After conditioning for three cycles (Fig. S6), plating/ stripping proceeded with a lower overpotential and improved reversibility. Moreover, the Coulombic efficiency increased to ca. $88 \%$ during the initial several cycles and then remained steady over the 30th cycle (Fig. 2b). The insufficient Coulombic efficiency seems to be a result of the partially decomposed CMC/DME/THF electrolyte on the Au electrode and the formation of dead $\mathrm{Ca}$, which is electrically isolated from the electrode. This will be discussed in a different section of this paper along with the SEM/EDS results. Even if the Au working electrode is replaced by an electrode of another metal (e.g., Pt, Cu, and SUS), low overpotential, reversibility, and moderate Coulombic efficiency were still obtained (Fig. S7). On the other hand, the Ca plating/stripping behaviours were not observed when using electrolytes of $0.1 \mathrm{M} \mathrm{CMC}$ in diglyme and 0.1 M CMC in triglyme (Fig. S8). Considering the influence of the type of ether solvent and anion coordination on $\mathrm{Ca}$, the incompetency of these electrolytes arises due to the coordination of $\mathrm{Ca}$ with diglyme and triglyme being stronger than that of $\mathrm{Ca}$ with $\mathrm{DME}$ and $\mathrm{THF}^{37}$.

To provide direct evidence for $\mathrm{Ca}$ ionic conduction through the CMC/DME/THF electrolyte, we assembled a $\mathrm{Ca} \mid \mathrm{CMC} / \mathrm{DME} / \mathrm{THF}$ | Au cell and deposited $\mathrm{Ca}$ on the Au electrode at room temperature. In the disassembled cell, the deposits appeared as black powder on the Au electrode, which was washed with DME/THF (Fig. 3a). The black powder on the Au electrode and separator was removed and collected for XRD measurement, which revealed that the dominant product is $\mathrm{Ca}$ metal in the form of $\alpha-\mathrm{Ca}$ and $\beta-\mathrm{Ca}$, along with a small amount of $\mathrm{CaH}_{2}$ (Fig. S9). These broad peaks with a low intensity indicate a small size and a low crystallinity for all deposited materials. Then, the morphology of the deposits on the Au electrodes in CMC/DME/THF electrolyte were examined using SEM and EDS, and showed uniformly dispersed spherical particles (Figs. 3b,c, and S10). The spherical particle deposits have a shape similar to that of the Ca deposits prepared in the $\mathrm{Ca}\left(\mathrm{BH}_{4}\right)_{2}-\mathrm{LiBH}_{4}-\mathrm{THF}$ electrolyte $^{44}$. The EDS profile indicates that the deposits were mainly composed of $\mathrm{Ca}, \mathrm{O}$ and $\mathrm{C}$ with trace amounts of B (Fig. 3b). The large amount of $\mathrm{O}$ originated from the highly reactive fresh Ca deposits being briefly exposed to air before the EDS observation (Fig. 3c). The moderate amounts of $\mathrm{C}$ and $\mathrm{B}$ were likely due to electrolyte reduction at low potentials or residual CMC. The Ca weight ratio in a typical particle was calculated as $84 \%$ when contribution of $\mathrm{Au}$ content was eliminated. Accordingly, we concluded that the charge carrier in this system is $\mathrm{Ca}$.

In addition, black deposits were also observed on the glass separator after peeling it off of the Au electrode (Fig. S11). The deposits were collected from the glass separator for SEM and EDS analysis by sticking the carbon tape onto the glass and then peeling it off. The obtained images show that the deposits comprise Ca metal and are relatively larger than those on the Au electrode (Fig. S12). The poor adhesion to the Au electrode indicates that they easily lose contact with the electrode, resulting in the formation of dead Ca. This dead Ca formation and the electrolyte reduction at low potentials could cause the insufficient Coulombic efficiency during the $\mathrm{Ca}$ plating/stripping processes.

To investigate the anodic stability of the CMC/DME/THF electrolyte system, further CV measurements were performed using the Au electrodes with different voltage ranges (Fig. 4). The current density increased at a potential of approximately $4 \mathrm{~V}$, followed by suppression of further electrolyte breakdown and the absence of a significant cathodic current density during the reverse potential sweep even at a higher voltage of $\sim 7 \mathrm{~V}$. This finding is consistent with the behaviour observed in electrolytes containing carborane anions with magnesium and tetraethylammonium cations rather than electrolytes containing $\mathrm{BH}_{4}$ anions ${ }^{17,45}$. 
a

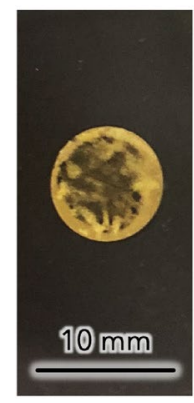

C

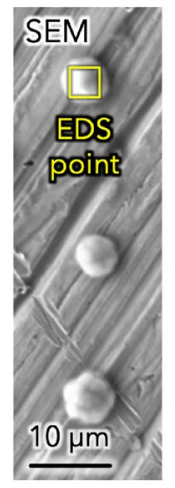

b

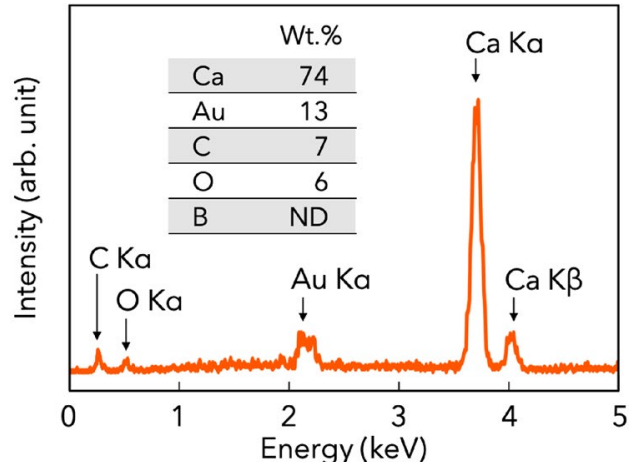

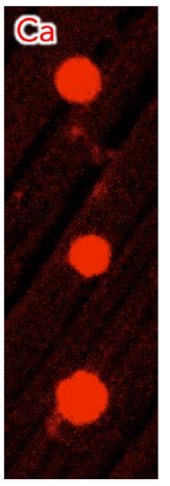
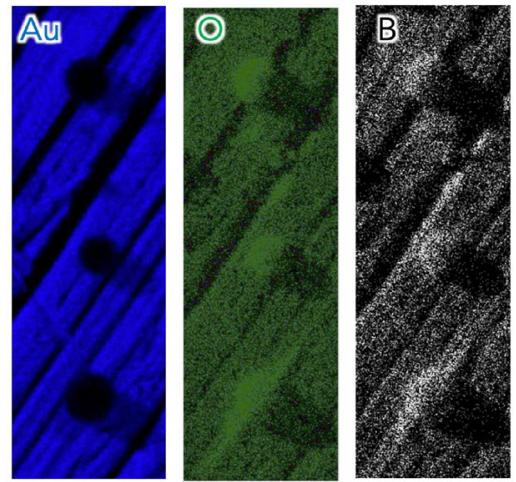

Figure 3. (a) Optical image of the Au electrode after a Ca plating process. (b) Energy-dispersive X-ray spectroscopy (EDS) profile within the yellow square. (c) Scanning electron microscopy (SEM) image of Ca deposits on the Au electrode after Ca plating in a Au | CMC/DME/THF | Ca cell, and EDS maps of Ca, Au, O, and $\mathrm{B}$.

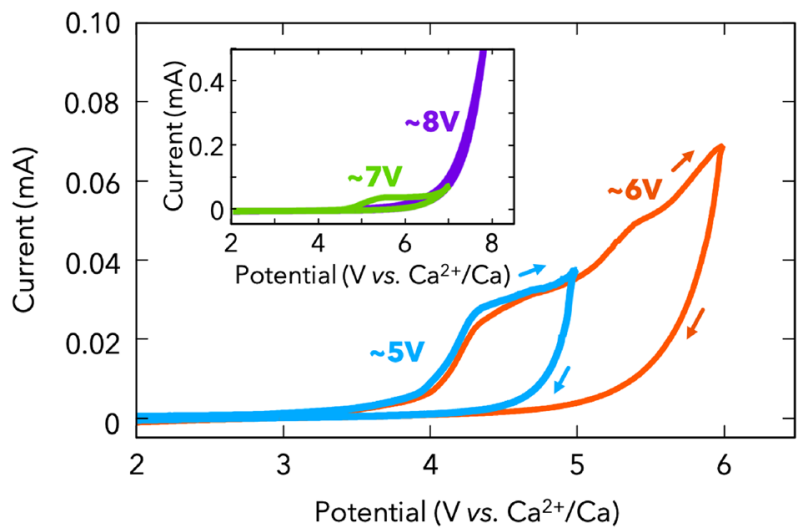

Figure 4. Cyclic voltammograms at $1 \mathrm{mV} \mathrm{s}^{-1}$ with different voltage ranges above $5 \mathrm{~V}$ (blue), $6 \mathrm{~V}$ (orange), $7 \mathrm{~V}$ (green), and $8 \mathrm{~V}$ (purple). Arrows indicate the sweeping direction during voltammetry. (d) Cycling performance of the $\mathrm{Ca} \mid \mathrm{CMC} / \mathrm{DME} / \mathrm{THF}$ | Ca cell at a current density of $0.02 \mathrm{~mA} \mathrm{~cm}^{-2}$.

Finally, to investigate the feasibility of the CMC electrolyte, we conducted an exploratory test involving a $\mathrm{Ca}-\mathrm{S}$ battery, which is a very promising system owing to its high theoretical energy density of $3202 \mathrm{Wh} \mathrm{L}^{-146}$. A $\mathrm{Ca}-\mathrm{S}$ battery, viz. Ca | CMC/DME/THF | S/C was tested with a current density of $167.2 \mathrm{~mA} \mathrm{~g}^{-1}(0.1 \mathrm{C}$ per S) at room temperature (Fig. 5a). The initial discharge and charge capacities of the $\mathrm{S} / \mathrm{C}$ cathode were up to 805 and $750 \mathrm{mAh} \mathrm{g}^{-1}$, respectively. Furthermore, it displayed a flat voltage plateau of $\sim 2.4 \mathrm{~V} \mathrm{vs}$. $\mathrm{Ca}^{2+} / \mathrm{Ca}$ corresponding to the sulfur redox reactions with $\mathrm{Ca}$ (Fig. $5 \mathrm{a}$ inset) ${ }^{47,48}$. To obtain information on the conversion reaction of the S/C cathode with $\mathrm{Ca}$, XPS measurements were performed on the pristine electrode and the electrode after discharge. The S $2 p$ spectra of the pristine S/C cathode display the spin-orbit-splitting doublet for elemental S with the $S 2 p_{3 / 2}$ and $S 2 p_{1 / 2}$ peaks at 164.0 and $165.2 \mathrm{eV}$, respectively (Fig. $5 \mathrm{~b}$ top). After the electrode discharged to $0.5 \mathrm{~V}$, the S 2 p signal spectra can be deconvoluted into three doublet peaks. In addition to peaks of the elemental 

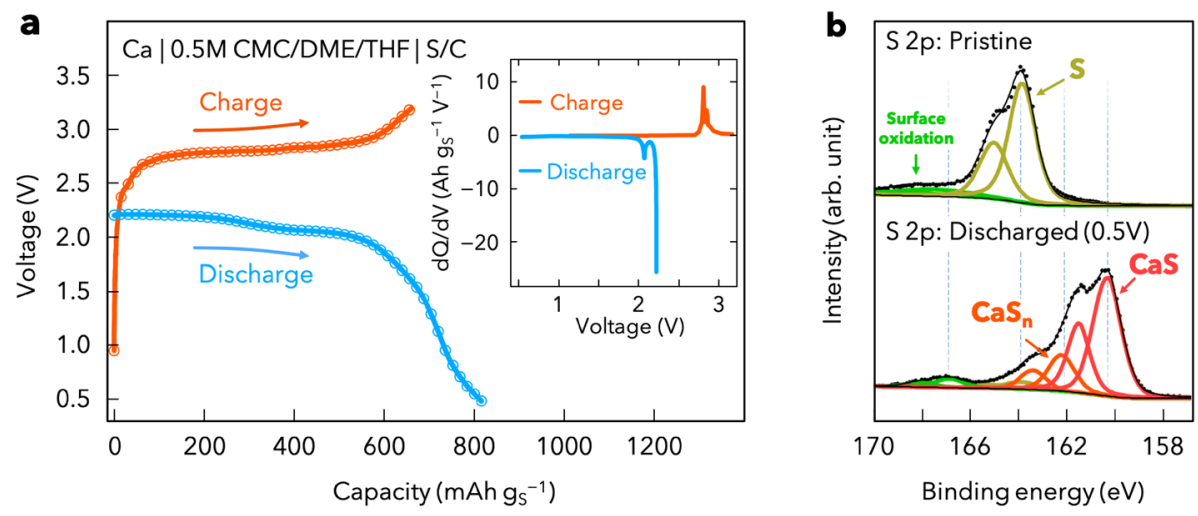

Figure 5. (a) Electrochemical performance of the $\mathrm{Ca}-\mathrm{S}$ batteries with the CMC/DME/THF electrolyte in a voltage window of from 0.5 to $3.2 \mathrm{~V}$; the inset shows differential capacities (dQ/dV), derived from the corresponding charge-discharge curve. (b) X-ray photoelectron spectroscopy (XPS) S 2p spectra of the S/C electrodes in the pristine (top) and discharged (bottom) states.

$\mathrm{S}$, new peaks at $160.3 \mathrm{eV}$ and $162.2 \mathrm{eV}$ attributed to terminal sulfur atom in polysulfides of $\mathrm{CaS}_{\mathrm{x}}(2 \leq \mathrm{x}<8)$ and calcium sulfide $(\mathrm{CaS})$, respectively, reflecting the effective conversion of $\mathrm{S}$ to sulfides (Fig. 5b bottom). This result demonstrates the practical applicability of the CMC electrolyte for $\mathrm{Ca}-\mathrm{S}$ batteries at room temperature, with a Ca metal anode.

In summary, we developed a highly stable and efficient fluorine-free Ca electrolyte based on a monocarborane anion, viz. a CMC electrolyte, for room-temperature Ca batteries. CMC salts were successfully prepared via simple cation exchange and heating processes, thus indicating that the synthetic method using an aqueous solution is scalable and very promising from an application perspective. The CMC salt exhibited low solubilities in THF and DME, but high solubility in the mixed solvent of DME/THF (1/1, v/v). The CMC electrolyte at $0.5 \mathrm{M}$ showed the most promising electrochemical performances, viz., a high conductivity, wide voltage window, and reversible Ca plating/stripping behaviour with high Coulombic efficiency. In a feasibility study, we used the $\mathrm{CMC}$ electrolyte in a $\mathrm{Ca}-\mathrm{S}$ battery exhibiting reversible discharge and charge abilities as well as a high capacity of $805 \mathrm{mAh} \mathrm{g}^{-1}$, demonstrating that the CMC electrolyte is compatible with a Ca-S battery system. The development of a promising electrolyte candidate based on complex hydrides compatible with Ca batteries will create future opportunities for exploring other related complex hydride compounds as Ca salts ${ }^{26,49-52}$. In addition, the absence of fluorine and $\mathrm{CaF}_{2}$ formation in these materials will intrinsically pave the way for achieving high cyclability in Ca batteries. These findings will contribute toward the development of practical electrolytes for room-temperature rechargeable Ca batteries.

Received: 17 January 2021; Accepted: 22 March 2021

Published online: 06 April 2021

\section{References}

1. Goodenough, J. B. \& Park, K.-S. The Li-ion rechargeable battery: A perspective. J. Am. Chem. Soc. 135, 1167-1176. https://doi. org/10.1021/ja3091438 (2013).

2. Ponrouch, A. et al. Multivalent rechargeable batteries. Energy Storage Mater. 20, 253-262. https://doi.org/10.1016/j.ensm.2019.04. 012 (2019).

3. Liang, Y., Dong, H., Aurbach, D. \& Yao, Y. Current status and future directions of multivalent metal-ion batteries. Nat. Energy 5, 646-656. https://doi.org/10.1038/s41560-020-0655-0 (2020).

4. Muldoon, J., Bucur, C. B. \& Gregory, T. Quest for nonaqueous multivalent secondary batteries: magnesium and beyond. Chem. Rev. 114, 11683-11720. https://doi.org/10.1021/cr500049y (2014).

5. Zhang, X. Y. et al. Challenges and opportunities for multivalent metal anodes in rechargeable batteries. Adv. Funct. Mater. 30, 2004187. https://doi.org/10.1002/adfm.202004187 (2020).

6. Arroyo-de Dompablo, M. E., Ponrouch, A., Johansson, P. \& Palacin, M. R. Achievements, challenges, and prospects of calcium batteries. Chem. Rev. 120, 6331-6357. https://doi.org/10.1021/acs.chemrev.9b00339 (2020).

7. Ponrouch, A. \& Palacin, M. R. On the road toward calcium-based batteries. Curr. Opin. Electrochem. 9, 1-7. https://doi.org/10. 1016/j.coelec.2018.02.001 (2018).

8. Gummow, R. J., Vamvounis, G., Kannan, M. B. \& He, Y. Calcium-ion batteries: Current state-of-the-art and future perspectives. Adv. Mater. 30, 1801702. https://doi.org/10.1002/adma.201801702 (2018).

9. Melemed, A. M., Khurram, A. \& Gallant, B. M. Current understanding of nonaqueous electrolytes for calcium-based batteries. Batter. Supercaps 3, 570-580. https://doi.org/10.1002/batt.201900219 (2020).

10. Aurbach, D., Skaletsky, R. \& Gofer, Y. The electrochemical behavior of calcium electrodes in a few organic electrolytes. J. Electrochem. Soc. 138, 3536-3545. https://doi.org/10.1149/1.2085455 (1991).

11. Ponrouch, A., Frontera, C., Barde, F. \& Palacin, M. R. Towards a calcium-based rechargeable battery. Nat. Mater. 15, $169-172$. https://doi.org/10.1038/nmat4462 (2016).

12. Forero-Saboya, J. et al. Understanding the nature of the passivation layer enabling reversible calcium plating. Energy Environ. Sci. 13, 3423-3431. https://doi.org/10.1039/d0ee02347g (2020).

13. Li, Z. Y., Fuhr, O., Fichtner, M. \& Zhao-Karger, Z. Towards stable and efficient electrolytes for room-temperature rechargeable calcium batteries. Energy Environ. Sci. 12, 3496-3501. https://doi.org/10.1039/c9ee01699f (2019). 
14. Shyamsunder, A., Blanc, L. E., Assoud, A. \& Nazar, L. F. Reversible calcium plating and stripping at room temperature using a borate salt. ACS Energy Lett. 4, 2271-2276. https://doi.org/10.1021/acsenergylett.9b01550 (2019).

15. Jay, R. et al. Comparative study of $\mathrm{Mg}\left(\mathrm{CB}_{11} \mathrm{H}_{12}\right)_{2}$ and $\mathrm{Mg}(\mathrm{TFSI})_{2}$ at the magnesium/electrolyte interface. ACS Appl. Mater. Interfaces 11, 11414-11420. https://doi.org/10.1021/acsami.9b00037 (2019).

16. Zhao-Karger, Z., Gil Bardaji, M. E., Fuhr, O. \& Fichtner, M. A new class of non-corrosive, highly efficient electrolytes for rechargeable magnesium batteries. J. Mater. Chem. A 5, 10815-10820. https://doi.org/10.1039/c7ta02237a (2017).

17. Wang, D. et al. Plating and stripping calcium in an organic electrolyte. Nat. Mater. 17, 16-20. https://doi.org/10.1038/nmat5036 (2018).

18. Orimo, S., Nakamori, Y., Eliseo, J. R., Züttel, A. \& Jensen, C. M. Complex hydrides for hydrogen storage. Chem. Rev. 107, 4111-4132. https://doi.org/10.1021/cr0501846 (2007).

19. Riktor, M. D. et al. The crystal structure of the first borohydride borate, $\mathrm{Ca}_{3}\left(\mathrm{BD}_{4}\right)_{3}\left(\mathrm{BO}_{3}\right)$. J. Mater. Chem. 21, 7188-7193. https:// doi.org/10.1039/c1jm00074h (2011).

20. Strauss, S. H. The search for larger and more weakly coordinating anions. Chem. Rev. 93, 927-942. https://doi.org/10.1021/cr000 19a005 (1993).

21. Korbe, S., Schreiber, P. J. \& Michl, J. Chemistry of the carba-closo-dodecaborate(-) anion, $\mathrm{CB}_{11} \mathrm{H}_{12}{ }^{-}$. Chem. Rev. 106, 5208-5249. https://doi.org/10.1021/cr050548u (2006).

22. Giri, S., Behera, S. \& Jena, P. Superhalogens as building blocks of halogen-free electrolytes in lithium-ion batteries. Angew. Chem. Int. Ed. 53, 13916-13919. https://doi.org/10.1002/anie.201408648 (2014).

23. Cuan, J. et al. Borohydride-scaffolded Li/Na/Mg fast ionic conductors for promising solid-state electrolytes. Adv. Mater. 31, 1803533. https://doi.org/10.1002/adma.201803533 (2018).

24. Kim, S. et al. A complex hydride lithium superionic conductor for high-energy-density all-solid-state lithium metal batteries. Nat. Commun. 10, 1081. https://doi.org/10.1038/s41467-019-09061-9 (2019).

25. Tang, W. S. et al. Liquid-like ionic conduction in solid lithium and sodium monocarba-closo-decaborates near or at room temperature. Adv. Energy Mater. 6, 1502237. https://doi.org/10.1002/aenm.201502237 (2016).

26. Mohtadi, R. \& Orimo, S. The renaissance of hydrides as energy materials. Nat. Rev. Mater. 2, 16091. https://doi.org/10.1038/natre vmats.2016.91 (2017).

27. Mohtadi, R., Remhof, A. \& Jena, P. Complex metal borohydrides: multifunctional materials for energy storage and conversion. J. Phys. Condens. Matter 28, 353001. https://doi.org/10.1088/0953-8984/28/35/353001 (2016).

28. Tutusaus, O. et al. An efficient halogen-free electrolyte for use in rechargeable magnesium batteries. Angew. Chem. Int. Ed. 54, 7900-7904. https://doi.org/10.1002/anie.201412202 (2015).

29. Dong, H. et al. High-power Mg batteries enabled by heterogeneous enolization redox chemistry and weakly coordinating electrolytes. Nat. Energy 5, 1043-1050. https://doi.org/10.1038/s41560-020-00734-0 (2020).

30. Tiritiris, I. \& Schleid, T. Dodekahydro-closo-dodekaborate der schweren Erdalkalimetalle aus wäßriger Lösung: $\mathrm{Ca}\left(\mathrm{H}_{2} \mathrm{O}\right)_{7}\left[\mathrm{~B}_{12} \mathrm{H}_{12}\right]$ - $\mathrm{H}_{2} \mathrm{O}, \mathrm{Sr}\left(\mathrm{H}_{2} \mathrm{O}\right)_{8}\left[\mathrm{~B}_{12} \mathrm{H}_{12}\right]$ und $\mathrm{Ba}\left(\mathrm{H}_{2} \mathrm{O}\right)_{6}\left[\mathrm{~B}_{12} \mathrm{H}_{12}\right]$. Z. Anorg. Allg. Chem. 627, 1836-1845. https://doi.org/10.1002/1521-3749(200108) 627:8\%3c1836::Aid-zaac1836\%3e3.0.Co;2-a (2001).

31. Tang, W. S. et al. Stabilizing lithium and sodium fast-ion conduction in solid polyhedral-borate salts at device-relevant temperatures. Energy Storage Mater. 4, 79-83. https://doi.org/10.1016/j.ensm.2016.03.004 (2016).

32. Stavila, V. et al. Probing the structure, stability and hydrogen storage properties of calcium dodecahydro-closo-dodecaborate. J. Solid State Chem. 183, 1133-1140. https://doi.org/10.1016/j.jssc.2010.03.026 (2010).

33. Unemoto, A. et al. Development of bulk-type all-solid-state lithium-sulfur battery using $\mathrm{LiBH}_{4}$ electrolyte. Appl. Phys. Lett. 105, 083901. https://doi.org/10.1063/1.4893666 (2014).

34. Sethio, D., Lawson-Daku, L. M. \& Hagemann, H. Computational study of the vibrational spectroscopy properties of boronhydrogen compounds: $\mathrm{Mg}\left(\mathrm{B}_{3} \mathrm{H}_{8}\right)_{2}, \mathrm{CB}_{9} \mathrm{H}_{10}{ }^{-}$and $\mathrm{CB}_{11} \mathrm{H}_{12}{ }^{-}$. Int. J. Hydrogen Energy 42, 22496-22501. https://doi.org/10.1016/j. ijhydene.2017.03.044 (2017).

35. Hu, Q., Zhao, H. \& Ouyang, S. Understanding water structure from Raman spectra of isotopic substitution $\mathrm{H}_{2} \mathrm{O} / \mathrm{D}_{2} \mathrm{O}$ up to 573 K. Phys. Chem. Chem. Phys. 19, 21540-21547. https://doi.org/10.1039/c7cp02065a (2017).

36. Toom, L., Kutt, A. \& Leito, I. Simple and scalable synthesis of the carborane anion $\mathrm{CB}_{11} \mathrm{H}_{12}$. Dalton Trans. 48, 7499-7502. https:// doi.org/10.1039/c9dt01062a (2019).

37. Hahn, N. T. et al. Influence of ether solvent and anion coordination on electrochemical behavior in calcium battery electrolytes. ACS Appl. Energy Mater. 3, 8437-8447. https://doi.org/10.1021/acsaem.0c01070 (2020).

38. Hahn, N. T. et al. The critical role of configurational flexibility in facilitating reversible reactive metal deposition from borohydride solutions. J. Mater. Chem. A 8, 7235-7244. https://doi.org/10.1039/d0ta02502j (2020).

39. Pu, S. D. et al. Current-density-dependent electroplating in Ca electrolytes: From globules to dendrites. ACS Energy Lett. 5, 2283-2290. https://doi.org/10.1021/acsenergylett.0c01153 (2020).

40. Johnson, J. W. \& Brody, J. F. Lithium closoborane electrolytes: III. Preparation and characterization. J. Electrochem. Soc. 129, 2213-2219. https://doi.org/10.1149/1.2123477 (1982).

41. Mohtadi, R., \& Tutusaus, O. High Concentration Electrolyte For Magnesium Battery Having Carboranyl Magnesium Salt in Mixed Ether Solvent. US patent no. US 2018/015917 A1. (2018).

42. Deetz, J. D., Cao, F., Wang, Q. \& Sun, H. Exploring the liquid structure and ion formation in magnesium borohydride electrolyte using density functional theory. J. Electrochem. Soc. 165, A61-A70. https://doi.org/10.1149/2.0321802jes (2018).

43. Tuerxun, F. et al. Effect of interaction among magnesium ions, anion, and solvent on kinetics of the magnesium deposition process. J. Phys. Chem. C 124, 28510-28519. https://doi.org/10.1021/acs.jpcc.0c08268 (2020).

44. Jie, Y. et al. Electrolyte solvation manipulation enables unprecedented room-temperature calcium-metal batteries. Angew. Chem. Int. Ed. 59, 12689-12693. https://doi.org/10.1002/anie.202002274 (2020).

45. Hahn, N. T. et al. Enhanced stability of the carba- closo-dodecaborate anion for high-voltage battery electrolytes through rational design. J. Am. Chem. Soc. 140, 11076-11084. https://doi.org/10.1021/jacs.8b05967 (2018).

46. Yu, X., Boyer, M. J., Hwang, G. S. \& Manthiram, A. Toward a reversible calcium-sulfur battery with a lithium-ion mediation approach. Adv. Energy Mater. 9, 1803794. https://doi.org/10.1002/aenm.201803794 (2019).

47. Scafuri, A. et al. Spectroscopic insights into the electrochemical mechanism of rechargeable calcium/sulfur batteries. Chem. Mater. 32, 8266-8275. https://doi.org/10.1021/acs.chemmater.0c02074 (2020).

48. Li, Z. et al. Rechargeable calcium-sulfur batteries enabled by an efficient borate-based electrolyte. Small 16, e2001806. https://doi. org/10.1002/smll.202001806 (2020).

49. Matsuo, M. \& Orimo, S. Lithium fast-ionic conduction in complex hydrides: Review and prospects. Adv. Energy Mater. 1, 161-172. https://doi.org/10.1002/aenm.201000012 (2011).

50. Unemoto, A., Matsuo, M. \& Orimo, S. Complex hydrides for electrochemical energy storage. Adv. Funct. Mater. 24, $2267-2279$. https://doi.org/10.1002/adfm.201303147 (2014).

51. Udovic, T. J. et al. Exceptional superionic conductivity in disordered sodium decahydro-closo-decaborate. Adv. Mater. 26, 76227626. https://doi.org/10.1002/adma.201403157 (2014).

52. Kisu, K. et al. Magnesium borohydride ammonia borane as a magnesium ionic conductor. ACS Appl. Energy Mater. 3, 3174-3179. https://doi.org/10.1021/acsaem.0c00113 (2020). 


\section{Acknowledgements}

This work was supported by the JSPS KAKENHI Grants-in-Aid for Young Scientists (No. 19K15305 and 19K15666), a Grant-in-Aid for Scientific Research on Innovative Areas ('Hydrogenomics', No. JP18H05513). It was also supported by the Core Research Clusters for Materials Science and the Advanced Target Project of WPI-AIMR from Tohoku University. The authors would like to appreciate Mr. Lombardo Loris Giovanni and Mr. Ko Youngdon for the helpful discussion about the thermal analysis (EPFL), and Dr. Rana Mohtadi for her advice on preparing this manuscript, especially about characterization for the monocarborane cluster materials (Toyota Research Institute of North America). The authors would like to thank H. Ohmiya and N. Warifune (Tohoku University) for their technical assistance.

\section{Author contributions}

K.K., S.K. and S.O. designed the research. K.K. prepared all electrolyte materials and performed the electrochemical measurements. T.S. participated in the electrolyte preparation. Z.K. and A.Z. performed thermal analysis measurements. K.K. worte the manuscript. All authors discussed and commented on the manuscript.

\section{Competing interests}

The authors declare no competing interests.

\section{Additional information}

Supplementary Information The online version contains supplementary material available at https://doi.org/ 10.1038/s41598-021-86938-0.

Correspondence and requests for materials should be addressed to K.K. or S.O.

Reprints and permissions information is available at www.nature.com/reprints.

Publisher's note Springer Nature remains neutral with regard to jurisdictional claims in published maps and institutional affiliations.

(c) (i) Open Access This article is licensed under a Creative Commons Attribution 4.0 International License, which permits use, sharing, adaptation, distribution and reproduction in any medium or format, as long as you give appropriate credit to the original author(s) and the source, provide a link to the Creative Commons licence, and indicate if changes were made. The images or other third party material in this article are included in the article's Creative Commons licence, unless indicated otherwise in a credit line to the material. If material is not included in the article's Creative Commons licence and your intended use is not permitted by statutory regulation or exceeds the permitted use, you will need to obtain permission directly from the copyright holder. To view a copy of this licence, visit http://creativecommons.org/licenses/by/4.0/.

(C) The Author(s) 2021 